\title{
Softening in Reinforced Concrete Beams and Frames
}

\author{
By Zdeněk P. Bažant,'1 Fellow, ASCE, Jiaying Pan,2 \\ and Gilles Pijaudier-Cabot, ${ }^{3}$ Student Member, ASCE
}

\begin{abstract}
Aвstract: The softening postpeak load-deflection relation for cracking reinforced concrete beams and frames is analyzed by layered finite elements. Concrete is assumed to exhibit strain softening in both tension and compression, and the steel reinforcement is elastic-plastic. The bending theory assumptions are used and bond slip of reinforcement is neglected. It is shown that the model can satisfactorily approximate the existing test results for softening beams and frames. At the same time, the constitutive laws with strain softening, including those of continuum damage mechanics, are shown to lead to spurious sensitivity of results to the chosen finite element size, similar to that documented before for other strain-softening problems. In analogy to the finite element crackband model, this problem can be overcome if the minimum admissible element size is specified as a cross section property; its suitable value appears to be equal to the beam depth.
\end{abstract}

\section{INTRODÜCTION}

When loaded to destruction, reinforced concrete beams can sometimes exhibit a softening response in which the load, after reaching its peak value, does not follow a constant-load yield plateau but gradually declines at increasing displacement. For prestressed concrete beams and short columns, such softening behavior is typical. Due to the absence of yield plateau, the conditions of plastic limit analysis are not satisfied, which means that the ultimate load of a statically indeterminate beam or frame is not correctly predicted from a plastic hinge mechanism. Generally, the maximum load is less, since one plastic hinge may already soften before another hinge reaches its maximum bending moment. The maximum load can be either much less than the plastic limit load, or only slightly less. No method to predict the maximum load for a softening beam or frame is available at present, although some aspects of the problem have been clarified in previous works $(1,11,12,15,16,19,20-25,29)$. Formulation and verification of such a method is the objective of this work.

For strain-softening beams and frames, the bound theorems of plasticity do not apply, and the entire load-deflection diagram must be calculated in order to determine the maximum load or the load at which collapse occurs. A reasonable assumption for calculations appears to be to describe the

'Prof. of Civ. Engrg., Northwestern Univ., Evanston, IL 60201.

${ }^{2}$ Visiting Scholar at Northwestern Univ., Evanston, IL 60201; on leave from China Acad. of Railway Sci., Beijing, China.

${ }^{3}$ Grad. Res. Asst., Northwestern Univ., Evanston, IL 60201; on leave from Laboratoire de Mécanique et Technologie, Cachan, France.

Note. Discussion open until May 1, 1988. Separate discussions should be submitted for the individual papers in this symposium. To extend the closing date one month, a written request must be filed with the ASCE Manager of Journals. The manuscript for this paper was submitted for review and possible publication on November 4, 1986. This paper is part of the Journal of Structural Engineering, Vol. 113, No. 12, December, 1987. CASCE, ISSN 0733-9445/87/0012-2333/\$01.00. Paper No. 22020. 
effect of progressive distributed cracking in concrete as strain softening of the material. Then, however, one must cope with strain-localization instabilities caused by strain softening, which have been previously demonstrated for statically indeterminate beams; see Ref. 1, in which the effect of curvature localization length and the effect of the end restraint stiffness were determined by stability analysis.

Another way of analyzing strain-softening frames is to assume that strain softening is localized into point hinges, just as in plastic limit analysis $(14-16,20,21,23)$. Then, however, the response of the beam or frame cannot be deduced from material properties, and the behavior of the softening hinge must be determined directly. Moreover, the effect of the curvature localization length cannot be captured. For this reason, we attempt here to analyze the problem on the basis of strain-softening material properties, in a manner analogous to other problems for strain softening in concrete and rock that have been solved recently.

We also need to address the question of numerical step-by-step algorithm, since strain softening may cause divergence of iterations. To achieve stability through the peak and postpeak regions, calculations must be done under displacement control, which makes it possible to follow the response up to the snapback point, if such a point exists. Crisfield's arclength method (13) would no doubt make it possible to follow the response even through and after the snapback point; however, this behavior, which is relevant primarily for dynamic response, will not be our objective.

In this study, we attempt to model softening of beams and frames using material behavior assumptions that are consistent with those used recently in a number of other problems. Strain softening associated with a certain characteristic length of the material has been used successfully to describe the fracture test data for concrete, both the maximum load data and the $R$-curves, the size effect, deflections of cracked reinforced concrete beams, both short-time and long-time, and the effect of simultaneous drying or wetting, or simultaneous heating or cooling, on the creep of concrete specimens $(2,4,5,7-9,18)$. The fact that the same strain-softening material properties explain a broad range of phenomena lends confidence to this approach.

\section{Problem Statement}

We consider beams or frames that are made of a softening material and may be reinforced by elastic-plastic bars. The theory of bending is used, i.e., the cross sections are assumed to remain plane and normal to the deffection line. The deflections are small. The material behavior, considered to simulate concrete, exhibits strain softening for both tension and compression.

Two types of stress-strain relations will be used in the examples. One represents a special case of a recently introduced concrete damage model (24) and has the general triaxial form:

$\sigma=(1-\omega) C \varepsilon$

in which $\mathbf{C}=$ initial elastic material stiffness matrix; $\mathbf{\sigma}, \boldsymbol{\varepsilon}=$ column matrices of stress and strain components; and $\omega=$ damage measure (a scalar). Loading and unloading are distinguished by means of the loading function: $f(\tilde{\varepsilon})=\tilde{\varepsilon}-\kappa(\tilde{\varepsilon})$

where $k(\tilde{\varepsilon})$ is a hardening-softening parameter; $\tilde{\varepsilon}=\left[\left\langle\varepsilon_{1}\right\rangle^{2}+\left\langle\varepsilon_{2}\right\rangle^{2}+\left\langle\varepsilon_{3}\right\rangle^{2}\right]^{1 / 2}$ $=$ equivalent strain, representing the positive projection of the vector of principal strains $\varepsilon_{1}, \varepsilon_{2}, \varepsilon_{3}$; and the symbol \langle\rangle is defined as $\langle x\rangle=x$ if $x>0$ and $\langle x\rangle=0$ if $x \leq 0$. The evolution of damage is specified as follows:

1. For loading, i.e., for $f(\bar{\varepsilon})=0$ and $\dot{f}(\bar{\varepsilon})=0$ :

$\omega=1-(1-A) \frac{\varepsilon^{0}}{\tilde{\varepsilon}}-A e^{-B\left(\tilde{\varepsilon}-\varepsilon^{0}\right)} ; \quad \kappa(\tilde{\varepsilon})=\tilde{\varepsilon}$

2. For unloading or reloading, i.e., for $f(\tilde{\varepsilon}) \leq 0$, or for $f(\tilde{\varepsilon})=0$ and $\dot{f}(\tilde{\varepsilon})$ $<0$ :

$\dot{\omega}=0$

in which $E=$ Young's elastic modulus; $\varepsilon^{0}=$ the specified initial threshold of damage; and $A, B=$ empirical positive constants. Setting $\mathrm{k}(\tilde{\varepsilon})=\tilde{\varepsilon}$ keeps the current state on the loading surface during loading. We will use this damage model only for uniaxial stress, $\sigma$. Then, if the loading is monotonic, the damage model reduces to

1. For tension $\left(\varepsilon \geq 0, \varepsilon>\varepsilon^{0}\right)$ :

$\sigma=E\left[\left(1-A_{t}\right) \varepsilon^{0}+A_{t} \varepsilon e^{-B_{t}\left(\varepsilon-\varepsilon^{0}\right)}\right]$

2. For compression $\left(\varepsilon<0, \varepsilon<-\sqrt{2} \nu \varepsilon^{0}\right)$ :

$\sigma=-\left(1-A_{c}\right) \varepsilon^{0} \frac{E}{v \sqrt{2}}+A_{c} E \varepsilon \exp \left[B_{c}\left(\sqrt{2} v e+\varepsilon^{0}\right)\right]$

in which $\varepsilon=$ axial strain; and $\nu=$ Poisson ratio. According to past practice, we use here different values $A_{t}, B_{t}$ and $A_{c}, B_{c}$ of parameters $A$ and $B$ for tension and compression. Although this simple expedient would introduce a problem with continuity for general triaxial response, it poses no problem for uniaxial response.

As another type of uniaxial stress-strain relation for concrete, we will also use the approximate trilinear diagram shown in Fig. 1(b), which was used before, e.g., by Soliman and Yu (28). This diagram exhibits a yield plateau to reflect the effect of confinement introduced by stirrups.

The unloading-reloading stress-strain diagram of concrete is assumed to be a straight line passing through the origin. Its slope represents the secant modulus for the maximum strain reached [Figs. $1(a-c)$ ]. This behavior is a simplification of the real behavior of concrete; the unloading diagram is actually curved, with the stress changing its sign at finite strain. Such behavior would be difficult to analyze with the secant direct iteration algorithm that will be used here, since the concaveness of the unloading diagram at opposite stress and strain signs would cause divergence.

The reinforcement is characterized by an elastic perfectly plastic stressstrain relationship [Fig. 1(c)].

Our objective is to calculate the maximum load, $P_{\max }$, of a given beam or frame, as well as the entire load-deflection diagram. The shape of this 

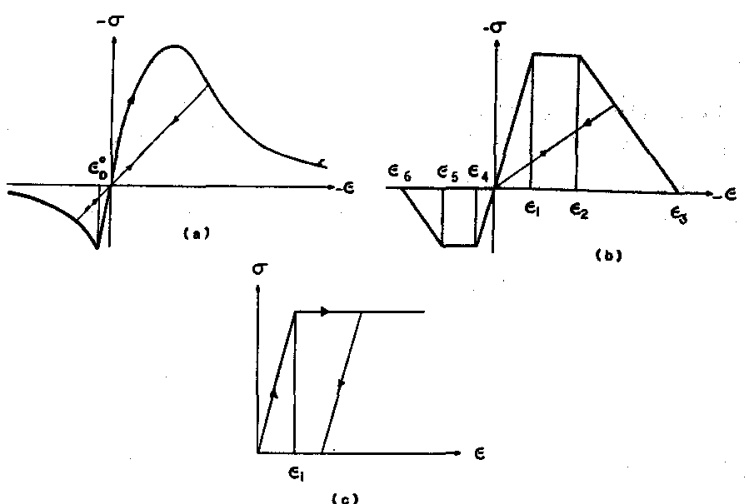

FIG. 1. Stress-Strain Relations for: (a-b) Concrete; (c) Steel

diagram, including the postpeak softening, is important for determining ductility and energy absorption capability of the structure. To be able to calculate the postpeak behavior, we assume that the structure is loaded in a displacement-controlled manner, i.e., the increments of the load-point displacement, $w$, are prescribed and the load, $P$, is solved as a reaction.

\section{Solution by Layered Finite Elements}

Even for monotonically increasing displacement $w$, unloading may take place at points adjacent to a strain-softening zone. Since the unloading may occur after previous inelastic deformations within various portions of the cross section, the shape of the unloading diagram for the momentcurvature relation is not unique. Obviously, it is necessary to trace the stress-strain path independently at various distances from the neutral axis. The layered finite element technique (30) is suitable for this purpose.

The solution is carried out in small loading steps. Among various possible step-by-step algorithms, we choose the direct iteration method (27). The algorithm may be briefly stated as follows:

1. Read the input data on structure geometry and material properties. Initialize.

2. Loop on loading steps with prescribed increments $\Delta w$ of controlled displacement $w$.

3. Store the values of nodal displacements (deflections and rotations of nodal cross sections) at the end of the preceding load step. Also store the maximum strains, $\varepsilon_{\max }$, and the minimum strains, $\varepsilon_{\min }$, achieved up to this step in every layer and every nodal cross section.

4. Loop on the iterations for the load step.

5. Calculate the strains $\varepsilon$ at midpoints of all layers in all nodal cross sections from the values of nodal displacements at the end of the preceding load step, for the first iteration, or from the values obtained in the preceding iteration, for the subsequent iterations. For each point, check the unloading conditions $\varepsilon<\varepsilon_{\max }$ for tension and $\varepsilon>\varepsilon_{\min }$ for compression. According to the stress-strain diagram, calculate for each point from $\varepsilon$ the stress, $\sigma$, and the secant modulus, $E_{\mathrm{sec}}=\sigma / \varepsilon\left(\right.$ if $\varepsilon=0$ take $E_{\mathrm{sec}}=E$ ). Note that, on the unloading-reloading diagram of concrete [Figs. 1( $a-c)$ ], $E_{\text {sec }}=$ constant while for steel $E_{\mathrm{sec}}$ is variable. Using the $E_{\mathrm{sec}}$ values for the individual layers, calculate the stiffness matrix of each finite element (beam element). Assemble the structural stiffness matrix. Implement the boundary conditions, including the displacement control. Solve the system of equilibrium equations to obtain new nodal displacements. Compare these displacements with those from the preceding iteration, check the specified convergence criterion, but omit the convergence check for the first iteration. The criterion $\left|\left(\Sigma_{i} u_{i N}^{2} / \Sigma_{i} u_{i P}^{2}\right)-1\right| \leq t$ has been used; $u_{i N}, u_{i P}=$ new and previous values of the $i$ th displacement component, and $t=$ chosen tolerance, typically 0.01 . If the criterion is not met, return to step 4 and repeat step 5.

6. Calculate load $P$ as the reaction at the point of prescribed displacement, $w$. Calculate the internal forces (bending moment, axial force) for each finite element and the strains and stresses of all layers. Print the results as specified. Return to step 2 and start the next loading step, unless the last step has been reached.

In this algorithm, the secant structural stiffness matrix is repeatedly updated according to the newly calculated displacements. If the steps $\Delta w$ are small (usually $\Delta w=5 \%$ of $w$ at $P_{\text {ax }}$ ), only a few iterations are required to achieve convergence (if more than 10 iterations are needed, it is more efficient to reduce the loading step $\Delta w$ than to carry out more iterations). However, near the point of instability, which occurs, for displacement control, when the slope of the postpeak $P(w)$ diagram approaches the vertical, the convergence is slow. At the critical state with $d P / d w \rightarrow-\infty$, and beyond, the present algorithm does not converge, i.e, the snapback behavior cannot be calculated with it (however, Crisfield's arc-length method (13) could then be used).

The present algorithm does not permit the use of the complete actual curved unloading diagram of concrete because divergence would occur when $E_{\mathrm{sec}}<0$. The initial stiffness method (27) would avoid such situations of divergence; however, inelastic strains would have to be considered. The direct iteration method has been used because it is the easiest to program as it does not require analysis with inelastic strains.

\section{Numerical Implementation and Analysis of Test Data}

\section{Darvall and Mendis Tests (17)}

Darvall and Mendis (17) tested a number of simply supported beams that exhibit strain softening in the load-deflection diagram. As an example, we consider their beam A1 [Figs. 2(a-b)], with the following characteristics: (1) Standard cylindrical compression strength $41 \mathrm{MPa}$; (2) initial elastic modulus $30,000 \mathrm{MPa}$, (3) water-cement ratio of 0.45 ; (4) aggregate-cement ratio of 3.4 (ASTM type I); (5) maximum size of the aggregate 3/8 in. (9.53 $\mathrm{mm}$ ); (6) bar diameter [Fig. 2(b)] $12 \mathrm{~mm}$; and (7) steel yield strength 400 $\mathrm{MPa}$. The curvature at mispan was determined by measuring the rotation of two symmetrically located cross sections at the distance $152 \mathrm{~mm}$ apart.

Due to symmetry, we analyze only half of the span and divide it into eight elements. Each element is divided into 10 layers [Fig. 2(b)]. 


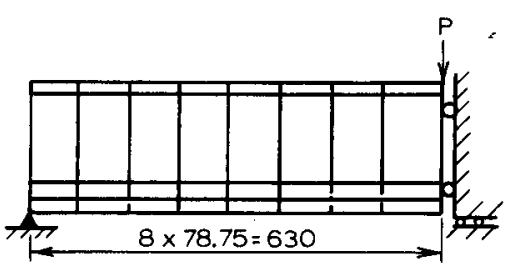

(a)

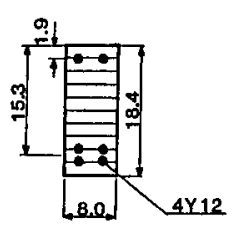

(b)

FIG. 2. Beam Tested by Darvall and Mendis (1985): (a) Structure; (b) Cross Section
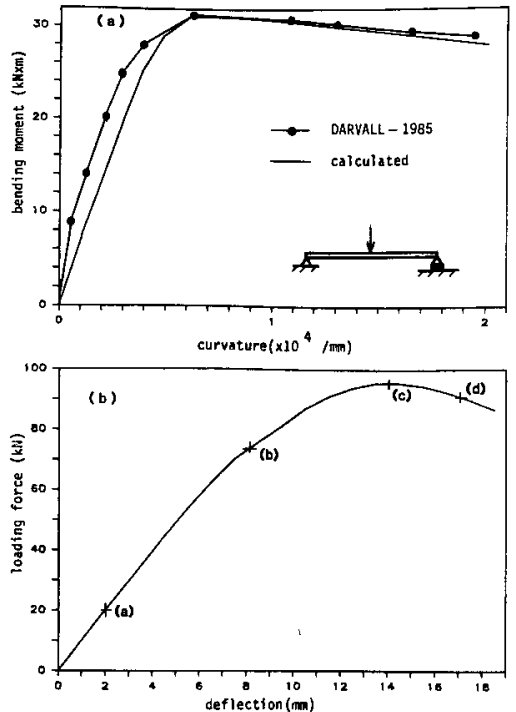

FIG. 3. Darvall and Mendis' Test (1985): (a) Comparison with Calculated Moment-Curvature Diagram (at Midspan); (b) Calculated Load-Deflection Curve (at Midspan)

The steel reinforcement is assumed to be elastic-perfectly plastic. The reinforcing bars are treated as additional layers with the properties of steel, having the same cross section as the bars.

The beam is solved on the basis of the damage stress-strain relation (Eq. 4) shown in Fig. 1(a). The following values of the parameters in Eq. 3 are obtained by fitting cylinder test data: $\varepsilon^{0}=10^{-4}$ and $E_{c}=30,000 \mathrm{MPa}$. For compression, $A_{c}=1.1$ and $B_{c}=1,000$. We assume $\nu=0.2$, while for tension, $A_{t}=0.8$ and $B_{t}=2.104$. The test results are shown on the moment-curvature diagram in Fig. $3(a)$ as the solid points. Good fit of the experimental data has been achieved. This confirms that the present approach can handle the postpeak decline of the moment-curvature diagram.

Figs. $4(a-d)$ show the sequence of the stress distribution in the midspan cross section corresponding to the points denoted as (a), (b), (c), (d) on the load-deflection curve obtained numerically [Fig. 3(b)]. In Fig. 4(a), the compression behavior is still elastic while there is already some cracking. Beginning with point (b), concrete is completely damaged in tension as strain softening occurs in compression. At the peak [Fig. 4(c)], concrete on the compression face is crushed and offers no resistance according to the assumptions of this analysis. Finally, in the postpeak decline [Fig. $4(d)$ ], the softening plastic hinge is almost formed.

Figs. $5(a-d)$ show for these points of loading the damage development. In each element, the damage variable characterizes the degree of microcracking (at the peak of the stress-strain diagram, $\omega=0$ in tension and $\omega$

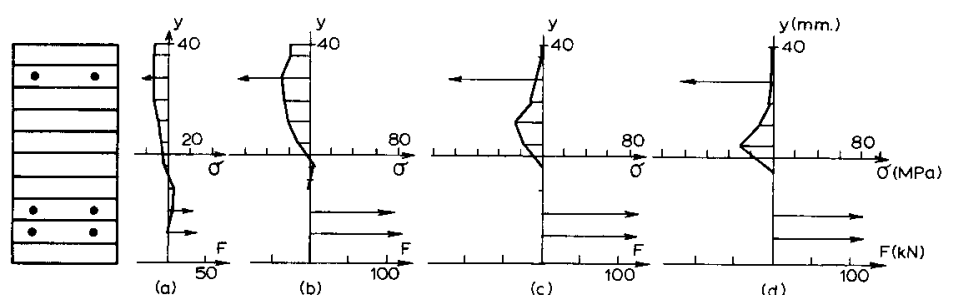

FIG. 4. Darvall and Mendis' Test (1985): Calculated Evolution of Stresses in Concrete and Forces in Steel at Midspan for Points (a), (b), (c), (d) on Load Deflection Curve [Fig. 3(b)]

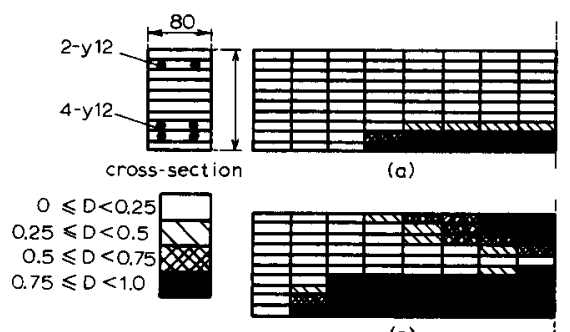

(c)

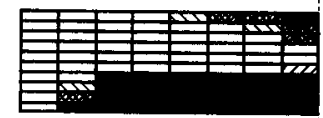

(b)

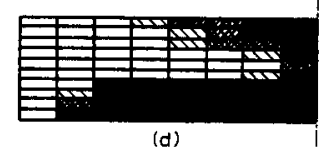

FIG. 5. Darvall and Mendis' Test (1985): Evolution of Damage in Concrete at Stages (a), (b), (c), (d) on Load-Deflection Curve [Fig. 3(b)]

$\approx 0.6$ in compression). The cracking zone first develops near the reinforcing bars and expands along the beam. At the peak (c), and in the softening part of the load-curvature diagram (d), the cracking zone does not expand in the axial direction while expanding further in the transverse direction. The cracking (damage) evolution is localized at midspan once the maximum load is reached.

\section{Nylander and Sahlin's Tests (26)}

Nylander and Sahlin tested 26 continuous beams, and two of them (beams number 9 and 19) exhibit softening response and are selected for analysis. These were continous beams with two symmetric long spans and a very short third span in the middle. Figs. $6(a-b)$ show the beam and its finite element discretization. In view of the symmetry of the beam and loads, symmetric deformation is assumed and only one-half of the beam is analyzed. The material properties are as follows: (1) Standard cylinder compression strength $30 \mathrm{MPa}$; initial Young's modulus 26,500 $\mathrm{MPa}$; maximum size of the aggregate $16 \mathrm{~mm}$; and steel yield strength $400 \mathrm{MPa}$. The other material parameters that are particular to the present model have been determined so as to yield optimum fit of test data (while giving generally the type of behavior reasonably expected for concrete). The following parameter values have been identified:

1. For the damage model [Fig. 1(a)], $v=0.2 ; \varepsilon_{D}^{0}=10^{-4} ; A_{t}=0.8 ; A_{c}=$ $0.9 ; B_{t}=2 \times 10^{4} ;$ and $B_{c}=900$. 


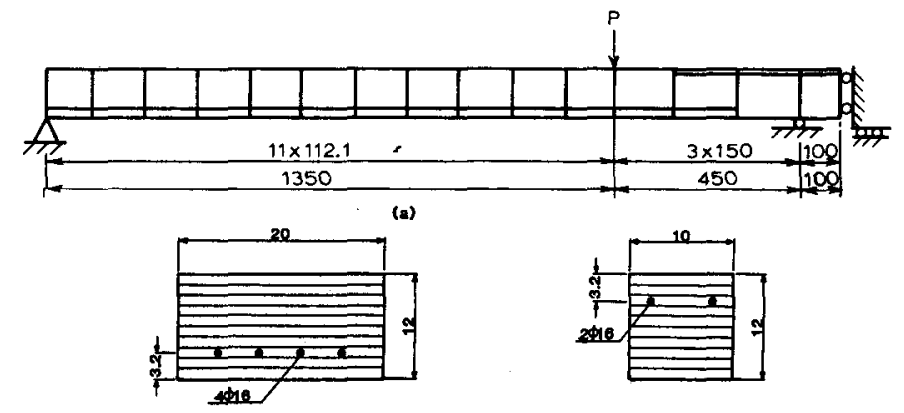

FIG. 6. Continuous Beam Tested by Nylander and Sahlin (1955): (a) Structure; (b) Cross Section

2. For the trilinear stress-strain diagram [Fig. $1(b)$ ], $E=25,000 \mathrm{MPa} ; \varepsilon_{1}$ $=10^{-3} ; \varepsilon_{4}=10^{-4} ; \varepsilon_{2}=4 \times 10^{-3} ; \varepsilon_{5}=1.1 \times 10^{-4} ; \varepsilon_{3}=2.5 \times 10^{-2} ;$ and $\varepsilon_{6}=5 \times 10^{-4}$

Fig. 7 shows the measured diagrams of load versus deflection under the load obtained with the present damage model, and the trilinear stressstrain diagram [Fig. 1(b)]. Point A corresponds to the formation of a softening hinge within the short span of the beam. While the beam is still statically indeterminate, a second softening hinge forms later at a higher load (point B), just before a sharp load drop indicating the failure of the specimen. This failure process is in good agreement with the experimental results.

\section{Cranston's Test (10)}

Cranston tested 10 pinned portal frames, of which frame $\mathrm{P}_{2}$, which $=$ exhibited softening, is chosen for analysis. The frame and its cross section

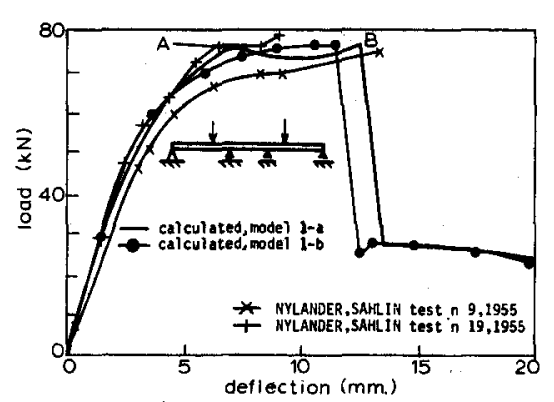

FIG. 7. Nylander and Sahlin' Tests (1955): Comparison with Curves of Load versus Load-Point Deflection Calculated with Damage Law and Trillinear Stress-Strain Curve [FIg. 1(a-b)] are shown in Fig. 8 along with the finite element subdivision. Although the final instability mode of the frame need not be symmetric, the bending moments calculated from the experimental data are in fact symmetric (10). Therefore, symmetric deformation is assumed for the analysis, permitting consideration of only one-half of the frame.

The reinforcement in beam segment $\overline{A B}$ (Fig. 8) consists of four steel bars placed at the bottom and two at the top. This arrangement is reversed for the beam segment BC, i.e., two bars are placed at the bottom and four at the top. In this case the simplified trilinear stress-strain curve [Fig. 1(b)] has been used for concrete. The concrete has the following properties: (1) Standard cylindrical compression strength $29 \mathrm{MPa}$; (2) initial Young's elastic modulus $25,500 \mathrm{MPa}$; (3) maximum aggregate size $3 / 8$ in. (9.5 mm); and (4) yield limit of steel $400 \mathrm{MPa}$. The remaining model parameters, which have been determined so as to optimize the fit of the test data, are as follows: for compression $\varepsilon_{1}=\varepsilon_{2}=\varepsilon_{3}=1.4 \times 10^{-3}$; for tension $\varepsilon_{4}=$ $10^{-4}, \varepsilon_{5}=5 \times 10^{-4}$, and $\varepsilon_{6}=1.5 \times 10^{-3}$. The measured load-deflection diagram is shown in Fig. 9.

According to the calculation, point $A$ on the load-deflection diagram in Fig. 9 corresponds to the beginning of yield in the tensile steel bars at midspan, and point $B$ corresponds to the beginning of strain softening in the compression zone at midspan. Point $\mathrm{C}$ refers to the beginning of yield in the tensile steel bars on top of the column, and point $D$ to the beginning of compression softening in concrete on top of the column.

\section{Effect of Element Size and Other Factors}

As expected on the basis of previous experience with other strainsoftening problems $(1,2,4,5,7,9)$, the results of the present finite element calculations in the softening range is found to be highly sensitive to the chosen element size. The limit of vanishing element size gives physically meaningless results, in which the curvature localizes into a segment of vanishing length and failure occurs at vanishing energy dissipation. Fig. 10 shows the load-deflection diagram obtained for Darvall's beam using different element sizes, while the element size is kept uniform all over the beam. As the element size decreases, a sharper postpeak drop of the load is observed due to curvature localization in the midspan element. For even smaller elements than those considered in Fig. 10, the postpeak equilibrium response curve would exhibit snapback, i.e., revert to positive slope.

A theoretically consistent way to avoid these difficulties is to use a nonlocal continuum model $(3,5)$, but a simpler expedient approach, which appears to work in many practical situations and was introduced in the crack-band model $(1,2,7,9)$ is to assume that the finite element size has a lower bound represented by the so-called minimum localization length $l_{b}$, which is a material property. This length represents the smallest segment into which the curvature in the beam can localize.

In the first study of curvature localization into a finite length segment of the beam (1), it was concluded that the element length should not be less than several times the aggregate size, $d_{a}$. In the crack-band model $(2,9)$, this limit was approximately estimated as $3 d_{a}$. This length roughly represents the smallest scale on which the heterogeneous aggregate material can be treated as a homogeneous continuum.

In the beam theory, however, another more stringent limitation arises 


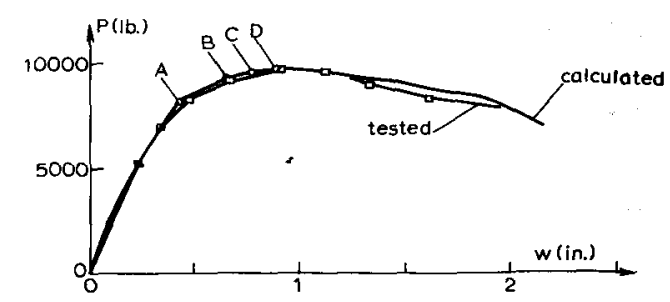

FIG. 9. Cranston's Test (1965): Comparison with Calculated Dlagram of Load versus Load-Point Deflection

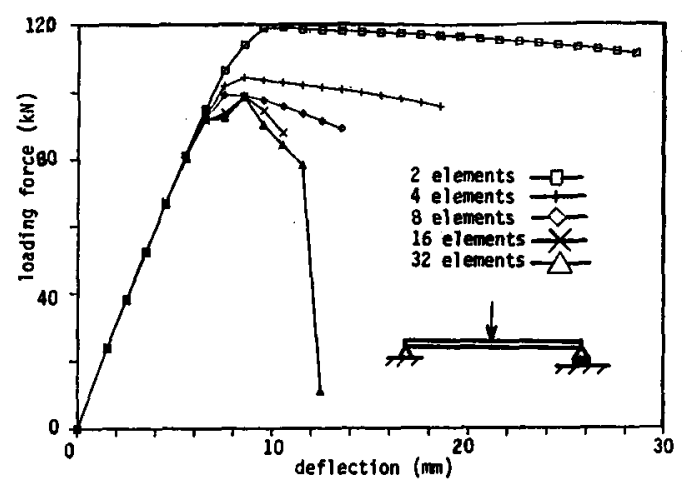

FIG. 10. Mesh Sensitivity of Load-Deflection Diagram for Darvall and Mendis' Beam

from Saint Venant's principle and the basic assumption of plane cross sections. It is known that, in general, curvature localization into segments whose lengths are shorter than the beam depth, $h$, cannot be correctly captured by the bending theory, since cross sections for such localizations do not remain plane, and a three-dimensional analysis is required. Applied forces or moments that are concentrated over a portion of the beam depth produce deformations that agree with the assumption of plane cross sections at a distance approximately $h$ from the cross section of load application, but not any closer. For this reason, it was required in the present fitting of test data that the finite element may not be smaller than approximately the beam depth $h$. The limit of three maximum aggregate sizes for the minimum element length never decides for concrete beams because the maximum aggregate size is always smaller than one-third of the beam depth.

Another property that greatly affects the results is the shape and the mean softening slope $R_{t}$ of the bending moment-curvature diagram (the mean tangential bending stiffness). By fitting test data of the type used here, the value of $R_{t}$ cannot be determined precisely. The reason is that the effects of $R_{t}$ and of the minimum curvature localization length $l_{b}$ are mutually compensating. To illustrate it, consider a beam segment of length $a\left(a \geq l_{b}\right)$ with a uniformly distributed bending moment. We consider two different choices $l_{b}$ and $l_{b}^{\prime}$ of the element length within segment $a$. In either case, it is found from stability analysis (1) that if a bending moment $d M$ is superimposed on an initial state of uniform curvature within the strain-

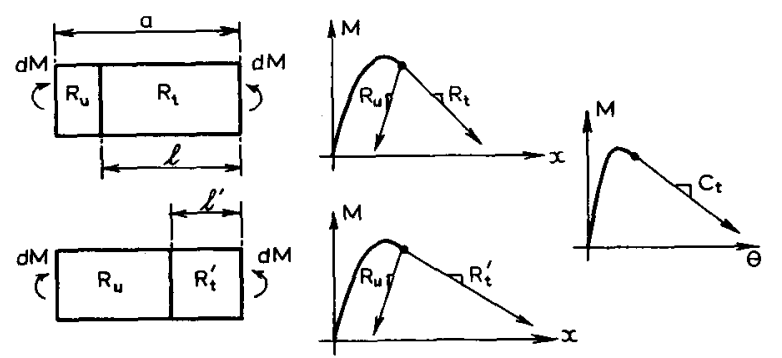

FIG. 11. Influence of Curvature Localization on Bending Stiffness

softening regime, then only the segment of length $l_{b}$ undergoes further loading (strain softening at increasing strain), while the remaining segment of length $a-l_{b}$ (or $a-l_{b}^{\prime}$ ) undergoes unloading and is characterized by a positive bending stiffness, $R_{u}$. The overall deformation properties of segment $a$ for both $l_{b}$ and $l_{b}^{\prime}$ are identical if the relative rotations of the ends of this segment are the same, i.e.

$\frac{d M}{R_{t}} l_{b}+\frac{d M}{R_{u}}\left(a-l_{b}\right)=\frac{d M}{R_{t}^{\prime}} l_{b}^{\prime}+\frac{d M}{R_{u}}\left(a-l_{b}^{\prime}\right)$

Solving for $R_{t}^{\prime}$, we see that for a change of the element size from $l_{b}$ to $l_{b}^{\prime}$, the overall rotational stiffness of the segment remains the same if the softening bending stiffness is changed simultaneously from $R_{t}$ to the value:

$R_{t}^{\prime}=\left(\frac{l_{b}}{R_{\mathrm{t}}}+\frac{l_{b}^{\prime}-l_{b}}{R_{\mathfrak{u}}}\right)^{-1}$

Eq. 6 is explained in Fig. 11. This figure shows two different softening bending stiffnesses $R_{t}$ and $R_{t}{ }^{\prime}$, which, when applied over localization segments of different lengths $l_{b}$ and $l_{b}^{\prime}$, yield for the moment-rotation relationship of a beam segment of length $a$ the same softening stiffness $C_{t}$ $\left(C_{t}<0\right)$.

The foregoing analysis means that the length of the curvature localization segment must be given in advance if the material strain-softening properties (or moment-curvature softening properties) should be determined from load-deflection measurements. Conversely, if the strainsoftening material properties were determined from other tests, then $l_{b}$ could be deduced from load-deflection measurements. A separate determination of the material softening properties can be based on fracture tests, especially when specimens of greatly different sizes are used. However, no companion fracture tests have been made for the presently considered test data.

The finite element results have also been found to be very sensitive to the reinforcement ratio.

\section{Conclusions}

The present study demonstrates that the softening postpeak behavior of the load-deflection diagrams or load-curvature diagrams of beams or 
frames can be explained in terms of strain-softening behavior of concrete. The strain-softening properties are approximately the same as used in a previous work to achieve agreement with the results of fracture tests of concrete and of deflection tests of cracked reinforced concrete beams. An efficient discretization procedure is provided by the layered finite element approach. The direct iteration method (iterative secant stiffness algorithm) for step-by-step loading provides a well-behaved convergent solution applicable in the softening regime, provided that unloading is not allowed to yield states at which the signs of strain and stress are opposite.

The numerical results reveal that a stress-strain relation with strain softening, including models of continuum damage mechanics, leads to spurious sensitivity to the finite element size and that a certain lower bound on the element size must be imposed as a cross section property. These problems will be analyzed further in a subsequent companion paper.

\section{ACKNOWLEDGMENTS}

Partial financial support under United States National Science Foundation No. MSM-8700830 to Northwestern University is gratefully acknowledged.

\section{Appendix I. Layered Finite Element Formulation Used}

To completely define the solution method and allow verification of results, we briefly summarize the finite element formulation (8). Each cross section is divided into $N_{l}$ layers, some of which may represent the reinforcing bars. The column matrices of element displacements and forces are $\mathbf{u}=\left(u_{i}, v_{i}, \theta_{i}, u_{j}, v_{j}, \theta_{j}\right)^{T}$ and $\mathbf{f}=\left(N_{i}, V_{i}, M_{i}, N_{j}, V_{j}, M_{j}\right)^{T}$, where $T$ denotes matrix transpose; $u=$ axial displacement; $v=$ transverse deflections; $\theta=$ rotation of cross section; and subscripts $i$ and $j$ refer to the adjacent cross sections $i$ and $j$ at the ends of element (Fig. 12). The internal forces are referred to the centroidal axis $x$.

The strain at any point $\mathrm{x}, \mathrm{y}$ (in cartesian coordinates $x, y$ ) is $\varepsilon(x, y)=$ $\partial u(x, y) / \partial x$, and the displacement in the axial direction is $u(x, y)=u(x, 0)-$ $y \partial v(x, 0) / \partial x$. We use finite elements with a cubic variation of $v$, and then for any point on the axis $x$

$u(x, 0)=(1-\xi) u_{i}+\xi u_{j}$

$v(x, 0)=\left(1-3 \xi^{2}+2 \xi^{3}\right) v_{i}+\left(3 \xi^{2}-2 \xi^{3}\right) v_{j}+L\left(\xi-2 \xi^{2}+\xi^{3}\right) \theta_{l}$

$+L\left(\xi^{3}-\xi^{2}\right) \theta_{j}$

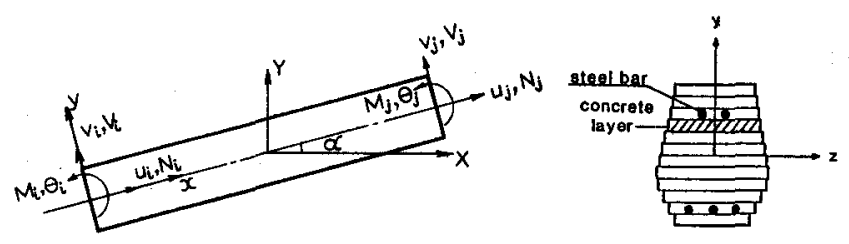

FIG. 12. Layered Finite Element where $\xi=x / L$; and $L=$ element length. Substituting these expressions into $u(x, y)=u(x, 0)-y \partial v(x, 0) / \partial x$ and $\varepsilon(x, y)=\partial u(x, y) / \partial x$, we obtain the geometric relation $\varepsilon(x, y)=$ Bu where

$\mathbf{B}=\frac{1}{L}[-1,6 \eta(1-2 \xi), 2 L \eta(2-3 \xi), 1,6 \eta(2 \xi-1)$,

$2 L \eta(1-3 \xi)]$

and $\eta=y / L$. Then, applying the virtual work principle to the beam element, we have $\delta \mathbf{u}^{T} \mathbf{f}=\int_{V} \delta \varepsilon^{T} \sigma d V=\delta \mathbf{u}^{T} \int_{V} \mathbf{B}^{T} \sigma d V$, and since this must hold for an arbitrary variation $\delta \mathbf{u}$, we obtain $\mathbf{f}=\int_{V} \mathbf{B}^{T} \boldsymbol{\sigma} d V=\int_{V} \mathbf{B}^{T} E_{s} \mathbf{B} \mathbf{u}$ $d V=\mathbf{k}_{e} \mathbf{u}$, where $V=$ element volume, $E_{s}$ secant modulus $\left(\sigma=E_{s} \varepsilon\right)$, and $\mathbf{k}_{e}=\int_{V} E_{s} \mathbf{B}^{T} \mathbf{B} d V=6 \times 6$ element stiffness matrix. Along $x$, we may integrate analytically and the integral over the cross section area we approximate by a sum over all the layers $m=1, \ldots, N_{l}$. Matrix $\mathbf{k}_{e}$ must then be transformed from element coordinates $(x, y)$ to global coordinates; $\mathbf{K}_{e}=\mathbf{T}^{T_{e}} \mathbf{k}_{e} \mathbf{T}$ where $\mathbf{T}=6 \times 6$ transformation matrix for coordinate rotation by angle $\alpha$, which represents the angle between axes $X$ and $x ; T_{11}=T_{22}=$ $T_{44}=T_{55}=\cos \alpha ; T_{33}=T_{66}=1 ; T_{12}=-T_{21}=T_{45}=-T_{56}=\sin \alpha ;$ and all other $T_{i j}$ are 0 . In this manner we obtain

$\mathbf{K}_{e}=\left[\begin{array}{cccccc}k_{1} & k_{2} & k_{4} & -k_{1} & -k_{2} & k_{7} \\ & k_{3} & k_{5} & -k_{2} & -k_{3} & k_{8} \\ & & k_{6} & -k_{4} & -k_{5} & 0.5 k_{6} \\ & & & k_{1} & k_{2} & -k_{7} \\ \operatorname{sym} & & & & k_{3} & -k_{8} \\ & & & & & k_{6}\end{array}\right]$

in which $k_{1}=Q L_{e}^{-1} c+12 S L_{e}^{-3} s ; k_{2}=\left(Q L_{e}^{-1}-12 S L_{e}^{-3}\right) c s ; k_{3}=Q L_{e}^{-1} s^{2}$ $+12 S L_{e}^{-3} c^{2} ; k_{4}=-R L_{e}^{-1} c-6 S L_{e}^{-2} s ; k_{5}=-R L_{e}^{-1} s+6 S L_{e}^{-2} c ; k_{6}=4$

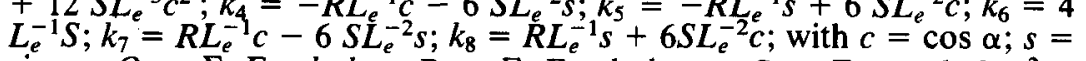
$\sin \alpha ; Q=\Sigma_{m} E_{s(m)} b_{m} h_{m} ; R=\Sigma_{m} E_{s(m)} b_{m} h_{m} y_{m} ; S=\Sigma_{m} E_{s(m)} b_{m} h_{m} y_{m}^{2} ;$ $b_{m}, h_{m}, y_{m}=$ width, thickness and centroidal coordinate for layer number $m$. Matrices $\mathbf{K}_{e}$ are finally assembled into the structural stiffness matrix $\mathbf{K}$. After the displacements are solved, the internal forces are calculated as $N_{i}=-N_{j}=\left[\left(X_{i}-X_{j}\right) c+\left(Y_{j}-Y_{j}\right) s\right] Q L_{e}^{-1}$

$+\left(\theta_{j}-\theta_{i}\right) R L_{e}^{-1}$

$V_{i}=-V_{j}=\left[\left(X_{j}-X_{i}\right) s-\left(Y_{j}-Y_{i}\right) c\right] 12 S L_{e}^{-3}$

$+\left(\theta_{i}+\theta_{j}\right) 6 S L_{e}^{-2}$

$M_{i}=\left[\left(X_{j}-X_{i}\right) c-\left(Y_{j}-Y_{i}\right) s\right] R L_{e}^{-1}$

$+\left[\left(X_{j}-X_{i}\right) s-\left(Y_{j}-Y_{i}\right) c\right] 6 S L_{e}^{-2}+2\left(2 \theta_{i}+\theta_{j}\right) S L_{e}^{-1}$

$M_{j}=\left[\left(X_{i}+X_{j}\right) c-\left(Y_{j}-Y_{i}\right) s\right] R L_{e}^{-1}$

$+\left[\left(X_{j}-X_{i}\right) S-\left(Y_{j}-Y_{i}\right) c\right] 6 S L_{e}^{-2}+2\left(\theta_{i}+2 \theta_{j}\right) S L_{e}^{-1}$ 
in which $X_{i}, X_{j}, Y_{i}, Y_{j}=$ the displacement components in the global $X$-and $Y$-directions at the element nodes $i$ and $j$.

\section{Appendix II. References}

1. Bažant, Z. P. (1976). "Instability, ductility and size effect in strain-softening concrete." J. Engrg. Mech. Div., ASCE, 102(2), 331-334. with discussions in Vol. 103, 357-358, 775-777; based on Struct. Engrg. Report No. 74-8/640 Northwestern University, 1974.

2. Bažant, Z. P. (1982). "Crack-band model for fracture of geomaterials." Proc. 4th Internatl. Conf. on Numer. Meth. in Geomech., held in Edmonton, Alberta, Canada, Z. Eisenstein, ed., Vol. 3, invited lectures, 1137-1152.

3. Bažant, Z. P. (1984). "Imbricate continuum and its variational derivation." J. of Engrg. Mech., 110(12), 1693-1712.

4. Bažant, Z. P. (1985). "Mechanics of fracture and progressive cracking in concrete structures." Chapter 1, Fracture mechanics applied to concrete structures, G. C. Sih, ed., Martinus Nijhoff Publ. B. V., The Hague, the Netherlands, 1-94.

5. Bažant, Z. P. (1985). "Fracture mechanics and strain-softening of concrete." Proc. U.S.-Japan Seminar Finite Element Analysis of R. C. Struct., held in Tokyo, Japan, American Society of Mechanical Engineers, C. Meyer, ed. $121-150$

6. Bažant, Z. P., Belytschko, T. B., and Chang, T. P. (1984). "Continuum theory for strain softening." J. of Engrg. Mech., 110(12), 1666-1692.

7. Bažant, Z. P., and Cedolin, L. (1982). "Fracture mechanics of reinforced concrete." J. Engrg. Mech., ASCE, 106, 1287-1306.

8. Bažant, Z. P., and Chern, J. C. (1985). "Concrete creep at variable humidity: Constitutive law and mechanism." Matériaux et constructions, RILEM, 18(13), Paris, France, 1-20.

9. Bažant, Z. P., Oh, B. H. (1983). "Crack-band theory for fracture of concrete." Matériaux et constructions, RILEM, 16(32), Paris, France 155-177.

10. Cranston, W. B. (1965). "Tests on reinforced concrete frames. 1: Pinned portal frames." Tech. Report TRA/392, Cement and Concrete Association, London, England.

11. Crisfield, M. A. (1982). "Local instabilities in the nonlinear analysis of reinforced concrete beams and slabs." Proc., Institute of Civil Engineers, 73(2), 135-145

12. Crisfield, M. A. (1984). "Difficulties with current numerical models for reinforced concrete and some tentative solutions." Proc. Int. Conf. Computer-Aided Analysis and Design of Concrete Struct., held in Split, Yugoslavia, F. Damjanic and E. Hinton et al., eds., publ. by Pineridge Yugoslavia, F. Damjanic and E.

13. Crisfield, M. A. (1984). "Overcoming limit points with material softening and strain localization." Numer. Meth. for Nonlinear Problems, C. Taylor et al., eds., 2, Pineridge, Swansea, England, 244-277.

14. Darvall, P. LeP. (1983). "Critical softening of hinges in indeterminate beams and portal frames." Civ. Engrg. Trans., I. E. Australia, CE25(3), 199-210.

15. Darvall, P. LeP. (1983). "Some aspects of softening in flexural members." Res. Report 3, Dept. of Civ. Engrg., Monash Univ., Clayton, Australia.

16. Darvall, P. LeP. (1983). "Critical softening of hinges in portal frames." $J$. Struct. Engrg., ASCE, 110(1), 157-162.

17. Darvall, P. LeP., and Mendis, P. A. (1984). "Elastic-plastic-softening analysis of plane frames." J. Struct. Engrg., ASCE, 111(4), 871-888.

18. Kang, Y. J., and Scordelis, A. C. (1980). "Nonlinear analysis of prestressed concrete frames." J. Struct. Div., ASCE, 106(2), 445-467.

19. Maier, G. (1967). "On elastic plastic structures with associated stress strain relations allowing for work softening." Meccanica, 2(1), 55-64.
20. Maier, G. (1967). "Extremum theorems for the analysis of elastic plastic structures containing unstable elements." Meccanica, 1(4), 235-242.

21. Maier, G. (1971) "Incremental plastic analysis in the presence of large displacements and physical instabilitizing effects." Int. J. of Solids and Struct., 7, 345-372.

22. Maier, G., Zavelani, A., and Dotreppe, J. C. (1973). "Equilibrium branching due to flexural softening." J. of Engrg. Mech. Div., ASCE, 99(4), 897-901.

23. Maier, G. (1971). "On structural instability due to strain-softening." IUTAM Symp. on Instability of Continuous Systems, held in Herrenhalb, Germany, Springer Verlag, West Berlin, 411-417.

24. Mazars, J. (1984). "Application de la mécanique de l'endommagement au comportment nonlinéaire et à la rupture du béton de structure," thesis presented to the University of Paris 6, at Paris, France, in partial fulfillment of the requirements for the degree of Doctor of Science.

25. Mróz, Z. (1985). "Current problems and new directions in mechanics of geomaterials." Chapter 24, Mechanics of geomatrials: Rocks, concretes, soils, Z. P. Bažant, ed., John Wiley and Son, Chichester, England, New York, N.Y., 539-566.

26. Nylander, H., and Sahlin, S. (1955). "Investigation of continuous concrete beams at far advanced compressive strains in concrete." Betong, 40(3), Translation No. 66, Cement and Concrete Association, London, England.

27. Owen, D. R. J., and Hinton, E. (1980). "Finite elements in plasticity: Theory and practice." Pineridge Press Ltd., Swansea, England.

28. Soliman, M. T. M., and Yu, C. W. (1967). "The flexural stress-strain relationship of concrete confined by rectangular transverse reinforcement." Magazine of Concrete Res., 19(61), 223-238.

29. Wood, R. H. (1968). "Some controversial and curious developments in the plastic theory of structures." Engineering Plasticity, J. Heyman and F. A. plastic theory eds., Cambridge Univ. Press, Cambridge, England, 665-691.

30. Zienkiewicz, O. C. (1977). The Finite Element Method. McGraw-Hill, London, England, New York, N.Y., 1977. 